\title{
12. ANALYSIS OF AMBIENT SEISMIC NOISE RECORDED BY DOWNHOLE AND OCEAN-BOTTOM SEISMOMETERS ON DEEP SEA DRILLING PROJECT LEG 78B1
}

\author{
Richard G. Adair, John A. Orcutt, and Thomas H. Jordan, Geological Research Division, \\ Scripps Institution of Oceanography ${ }^{2}$
}

\begin{abstract}
Ambient seismic noise at depth in the ocean crust is characterized using data from the Marine Seismic System (MSS), a vertical-component, digitally recording, short-period seismograph system which was part of the borehole instrumentation deployed on Deep Sea Drilling Project Leg 78B. The instrument package rested unclamped in Hole 395A, $516 \mathrm{~m}$ sub-basement. Reliable estimates of microseismic noise levels were obtained between 0.16 and $2.2 \mathrm{~Hz}$; instrument noise dominated outside this band. The observed microseismic noise was quasi-stationary on a time scale of 1 hr., but not 10. Although spectral shapes were stable, noise amplitudes grew with time over the 26-hr. observation period by 3 to $5 \mathrm{~dB}$. The borehole noise levels increased concurrently with local swell height, suggesting a causal relationship. An estimate of displacement power densities obtained early in the experiment had a peak value of $4 \times 10^{6} \mathrm{~nm}^{2} /$ $\mathrm{Hz}$ at $0.21 \mathrm{~Hz}$, and decreased at $80 \mathrm{~dB} /$ decade from $1 \times 10^{6} \mathrm{~nm}^{2} / \mathrm{Hz}$ at $0.33 \mathrm{~Hz}$ to $1 \mathrm{~nm}^{2} / \mathrm{Hz}$ at $1.9 \mathrm{~Hz}$. Noise levels observed at the seafloor near Hole 395A were greater than those observed in the borehole by a factor which increased with frequency from $10 \mathrm{~dB}$ at $0.2 \mathrm{~Hz}$ to $28 \mathrm{~dB}$ at $2 \mathrm{~Hz}$. This is consistent with noise propagating as a fundamental-mode Stoneley wave trapped near the sediment/seawater interface. If the relationship observed between noise at and below the seafloor during Leg 78B is a general one, ocean-bottom borehole noise levels could approach those at quiet continental sites.
\end{abstract}

\section{INTRODUCTION}

A knowledge of ambient seismic noise near the seafloor is needed in formulating optimal strategies for the deployment of marine seismometer systems. There are, however, no published studies of noise within the ocean crust and few of noise at the seafloor, especially of reliable, absolute noise levels. Most available measurements were made during the VELA Uniform Project sponsored by the Advanced Research Projects Agency in the 1960s. It was hoped that noise levels at the seafloor would be comparable to those on land (Prentiss and Ewing, 1963), but in fact they were found to be significantly higher (Bradner and Dodds, 1964; Schneider and Backus, 1964; Schneider et al., 1964; Latham and Sutton, 1966; Latham and Nowroozi, 1968). These studies suggest that the noise propagates as an evanescent wave (Stoneley wave) trapped near the ocean bottom/seafloor interface (Bradner et al., 1965; Latham and Sutton, 1966; Latham and Nowroozi, 1968), so reduced noise levels are expected within the ocean crust. The technology and expertise needed to implant instruments in the seafloor has only recently been developed, primarily by the Deep Sea Drilling Project (DSDP). Borehole seismometers have been used in oblique seismic experiments on several DSDP cruises (Stephen et al., 1980, Stephen et al., 1983), but the data are not suited for the quantitative analysis of seismic noise. A downhole seismometer system sponsored by the Defense Advanced Research Projects Agency, the Marine Seismic System (MSS), was de-

\footnotetext{
${ }^{1}$ Hyndman, R. D., Salisbury, M. H., et al., Init. Repts. DSDP, 78B: Washington (U.S. Govt, Printing Office).

2 Address: Geological Research Div., Scripps Institution of Oceanography, Univ. of California, San Diego, La Jolla, CA 92093.
}

ployed in Hole 395A (Fig. 1) during Leg 78B with the intent of recording high-quality noise and seismic data. This chapter presents the first quantitative characterization of ambient seismic noise within the ocean crust. In addition, noise characteristics at and below the seafloor are directly compared using data acquired with a nearby ocean-bottom seismograph (OBS) (See Fig. 1).

\section{INSTRUMENTATION AND OPERATIONS}

The borehole instrumentation of the MSS consisted of state-ofhealth sensors and two vertical-component, short-period seismometers (Teledyne Geotech model S-700'), one configured approximately $50 \mathrm{~cm}$ below the other. Each seismometer's output was split into three channels, and the gains of the resultant six channels were staggered with overlap to yield a dynamic range of $144 \mathrm{~dB}$ (Fig. 2). The data streams were filtered to prevent aliasing, digitized at 75 samples/s using a 10-bit digital word, and transmitted via cable to a shipboard recorder. The cable was also used to recover the borehole instrumentation package. The computed displacement response for the combined seismometer and filter stages is shown in Figure 3. The response is peaked near $11 \mathrm{~Hz}$, and rolls off at $12 \mathrm{~dB} /$ octave toward lower frequencies and at $15 \mathrm{~dB} /$ octave to the Nyquist frequency.

The borehole package was lowered from the Glomar Challenger to a sub-bottom depth of $609 \mathrm{~m}$ in Hole 395A (516 m sub-basement), where cave-ins blocked access to the bottom $55 \mathrm{~m}$. The package was in place for $\mathbf{2 9 . 5}$ hrs., but data were recorded only during the final 26 hrs., which included a refraction experiment (see Fig. 4). Although the seismometers were not clamped in the hole, the adjacent unfractured and massive wall rock doubtless promoted proper coupling. (The wallrock character was inferred from caliper and acoustic reflection logs conducted earlier during Leg 78B.) Ship motions conveyed to the package were quelled with $0.7 \mathrm{~km}$ of slack cable payed out on the seafloor. Noise samples were recorded between refraction shots and during breaks in the refraction experiment, both intentional and unintentional (when explosives failed to detonate). The times of relevant operations and events are shown in Figure 4.

Four triaxial ocean-bottom seismographs (OBSs) were dropped from the Lynch by seismologists from the University of Texas (UT) Institute of Geophysics. Each OBS was programmed to record $40 \mathrm{~s}$ of digital data with a sampling interval of $8.352 \mathrm{~ms}$ during the refraction shots 


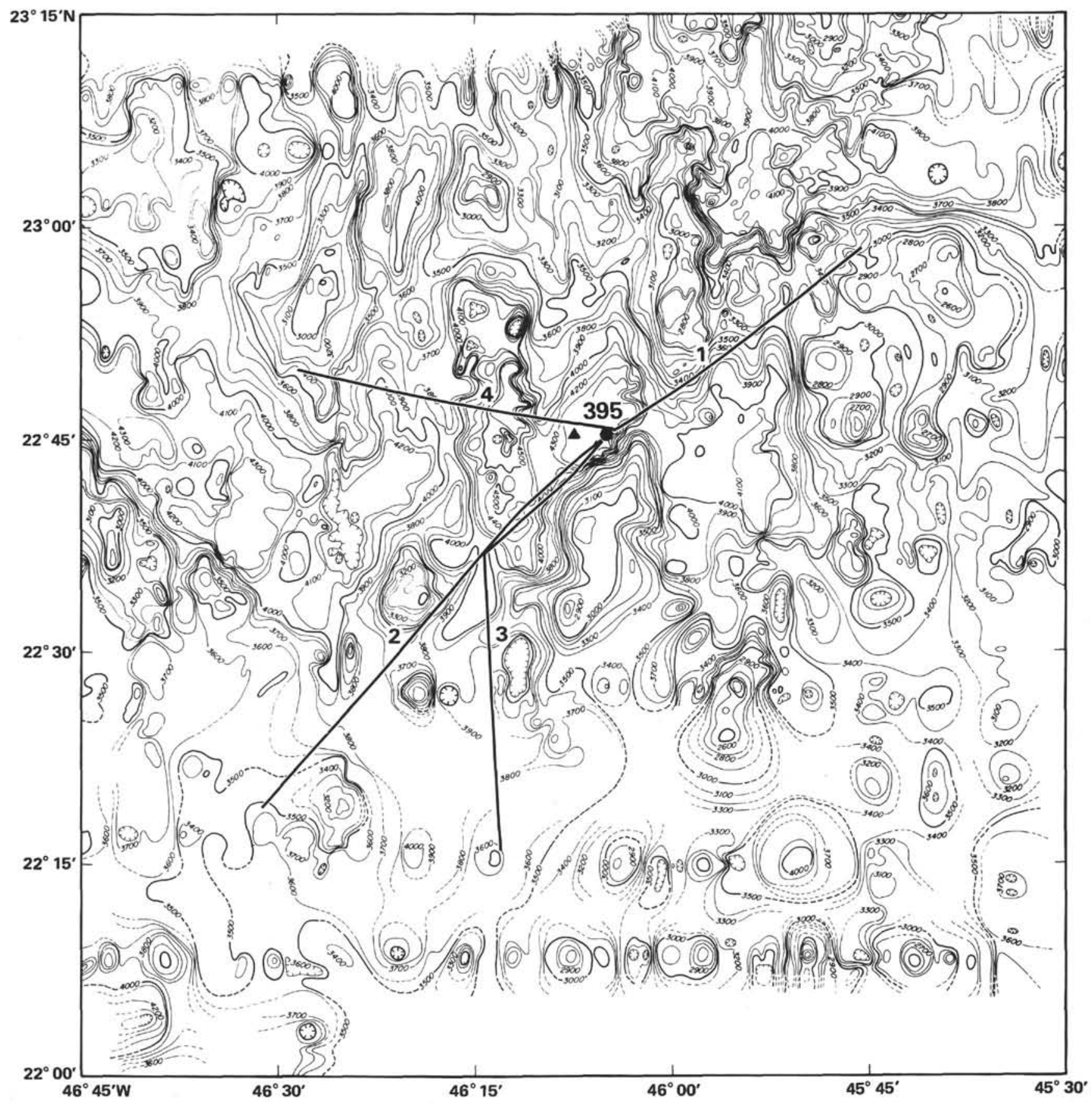

Figure 1. Location of the seismic instrumentation used in the Leg 78B noise experiment. The borehole instrumentation package of the Marine Seismic System (MSS) rested unclamped at the bottom of Hole $395 \mathrm{~A}\left(22^{\circ} 45.35^{\prime} \mathrm{N}, 46^{\circ} 04.91^{\prime} \mathrm{W}\right)$, drilled five years earlier on Leg 45 . The ocean-bottom seismometer (OBS) referred to here, one of four deployed during Leg 78B, was approximately 1 to $2 \mathrm{~km}$ west of Hole 395A. The OBS launch point $\left(22^{\circ} 45.50^{\prime} \mathrm{N}, 46^{\circ} 05.43^{\prime} \mathrm{W}\right)$ is shown as a triangle. Depths shown in corrected meters.

and the intentional shooting hiatus. The OBS seismometers were $10-\mathrm{Hz}$ Mark L6 geophones. The OBS displacement response (Fig. 3) increases with frequence at $18 \mathrm{~dB} /$ octave up to $10 \mathrm{~Hz}$, and at $6 \mathrm{~dB} /$ octave thereafter. A variety of malfunctions prevented data acquisition except from the vertical component of an OBS located approximately 1 to $2 \mathrm{~km}$ west of the borehole (see Fig. 1 for launch point). A more precise location based on water-wave arrivals was not possible, because recordings of the shots (but not of the noise) were severely clipped by frame resonances above $10 \mathrm{~Hz}$. Eleven 34-s samples of noise were obtained from the OBS data.

\section{DATA QUALITY}

Intrinsic earth noise was distinguished from instrument and ship noise on the basis of temporal and spectral characteristics. Spectral characteristics were determined from power densities and coherences computed in the manner described by Welch (1967). Time series were broken into segments which, after the mean was subtracted, were tapered with a normalized Hanning win- 


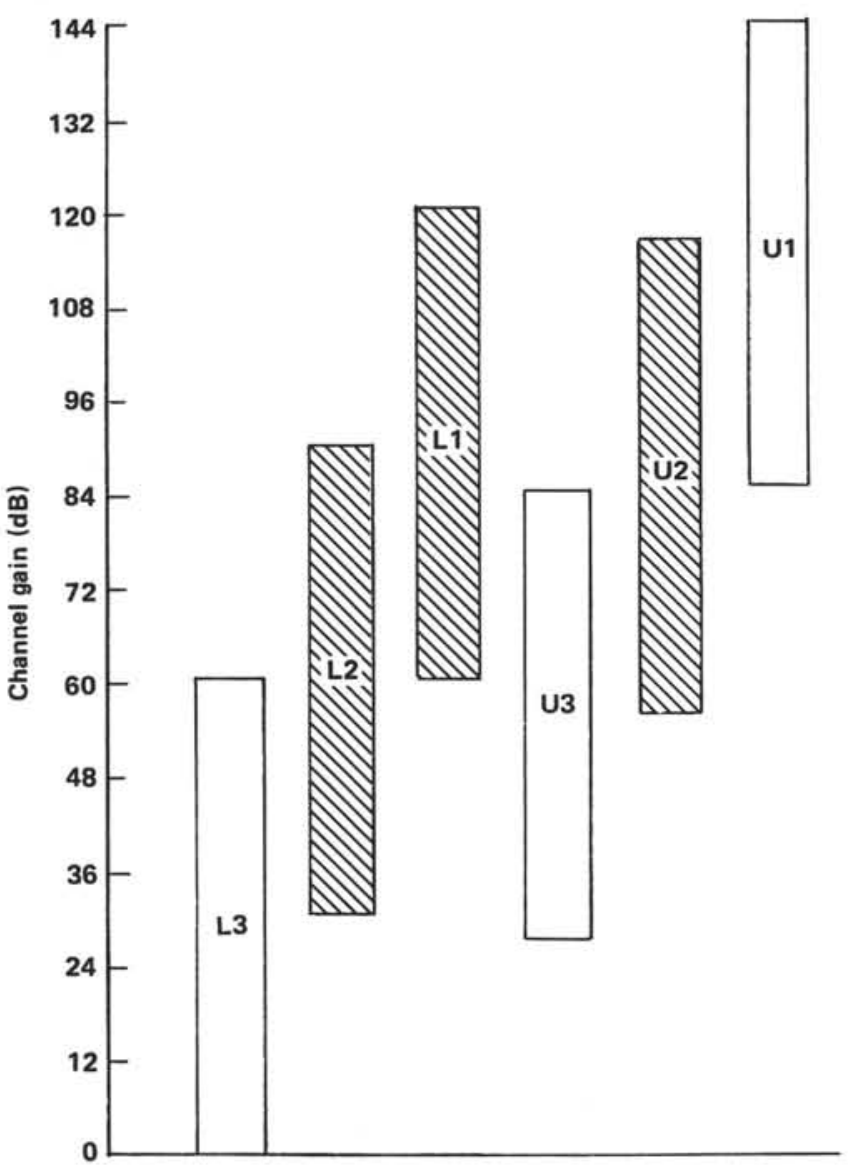

Figure 2. Schematic depiction of the MSS-data channel gains. The outputs of the two vertical-component seismometers, one configured $50 \mathrm{~cm}$ below the other, were split into 3 channels each, and the gains of the resultant 6 channels were staggered to yield $144 \mathrm{~dB}$ of dynamic range. "U" and "L" refer to the upper and lower seismometers, respectively. The use of a 10-bit unsigned digital word resulted in a range of $60 \mathrm{~dB}$ for each channel. Adjacent channels of a seismometer overlapped by $30 \mathrm{~dB}$; the upper seismometer gains were offset from the lower seismometer gains by $24 \mathrm{~dB}$. Because of noise and clipping, only the data from channels L1, L2, and $U 2$ could be used in this study.

dow, and Fourier-transformed. Auto-(power) and crossspectra were averaged (stacked) to reduce spectral estimate variance. Stable estimates were generally achieved with stacks of eight segments, although as many as 24 segments were used when available.

Of the six MSS data channels (Fig. 2), only three were usable for noise analysis (L1, U2, and L2); the highestgain channel (U1) was always clipped, and the two with the lowest gain (U3 and L3) were dominated by leastcount noise. An example of MSS data from channel L1 is shown in Figure 5. Typically, the data were dominated by monotonous, 1- to 4-s energy, whereas equally persistent high-frequency energy $(>10 \mathrm{~Hz})$ was of much lower amplitude. Features in Figure 5 attributed to instrument noise or not considered to represent ground motion are the dropped bit near $11 \mathrm{~s}$; the frequent, random, unidirectional (sensor mass up) transients of variable magnitude (e.g., near $10.5 \mathrm{~s}$ ); and the truncated, low-frequency peak centered at $6 \mathrm{~s}$ (a rare event). Single dropped bits, clearly resulting from instrument errors, were replaced with linearly interpolated values. The amplitudes and occurrence rates of the high-frequency transients generally decreased with time. Power densities of the MSS data and instrument noise are shown in Figure 6. The data were eight 13.65-s samples from channel L1 not corrected for instrument response. Electronics noise levels were estimated from RMS noise power values of one-half octave bandwidth provided by Teledyne Geotech. The least-count noise level is that expected from uniformly distributed errors resulting from the representation of a continuous variable by a finite, digital word (e.g. Otnes and Enochson, 1972). Neither of these sources of instrument noise dominated above $0.3 \mathrm{~Hz}$. Least-count noise became increasingly important at frequencies where the instrument response rolled off and resulted in diminished coherence of energy between the two MSS seismometers. Power densities at frequencies below $0.16 \mathrm{~Hz}$ are inferred to be dominated by instrument noise, on the basis of low coherence (Fig. 7).

The transients shown in Figure 5 are assumed to result either from movement of the unclamped borehole package or from pressure impulses caused by the escape of the casing gas (helium). The transients strongly resemble the MSS response to a step in displacement (Figure 8), and are taken as such for the purpose of determining power densities. The transients were modeled as a compound Poisson process (Appendix), and their predicted power density $P(f)$ at frequency $f$ is

$$
P(f)=2 \lambda\left\langle\alpha^{2}\right\rangle|H(f)|^{2}
$$

where $\lambda$ is the mean rate of transient occurrence, $\left\langle\alpha^{2}\right\rangle$ is the mean squared amplitude, and $H(f)$ is the Fourier transform of a transient of unit amplitude. $\lambda$ and $\left\langle\alpha^{2}\right\rangle$ were estimated for the data with the power densities shown in Figure 6, and the resulting $P(f)$ is plotted in the same figure as the curve labeled "Transient noise." The remarkably close agreement between the observed and predicted noise levels implies that energy beyond the break in power-density slope (near $2.2 \mathrm{~Hz}$ ) is concentrated almost entirely in the transients.

System noise levels are not known for the OBS, nor can coherences be estimated, since only the vertical component of one instrument was functional. The frequencies at which instrument noise dominated were qualitatively determined from uncorrected power densities (Fig. 9). The OBS frame resonance is dominant between 10 and $25 \mathrm{~Hz}$, and the essentially flat portions of the spectrum beyond $4 \mathrm{~Hz}$ and below $0.18 \mathrm{~Hz}$ imply instrumental sources of white noise. In addition, estimate stability could not be achieved below $0.18 \mathrm{~Hz}$ with the available time-series lengths.

Ship-generated acoustic signals undoubtedly contributed to local microseismic noise. Sources aboard the Challenger include machinery and the dynamic positioning system. The dynamic positioning system was silenced only once during the MSS deployment (0104-0120Z, 29 March), but since this was before the start of data recording, a quantitative assessment of its effects is not possible. Unpublished ocean-bottom noise spectra esti- 


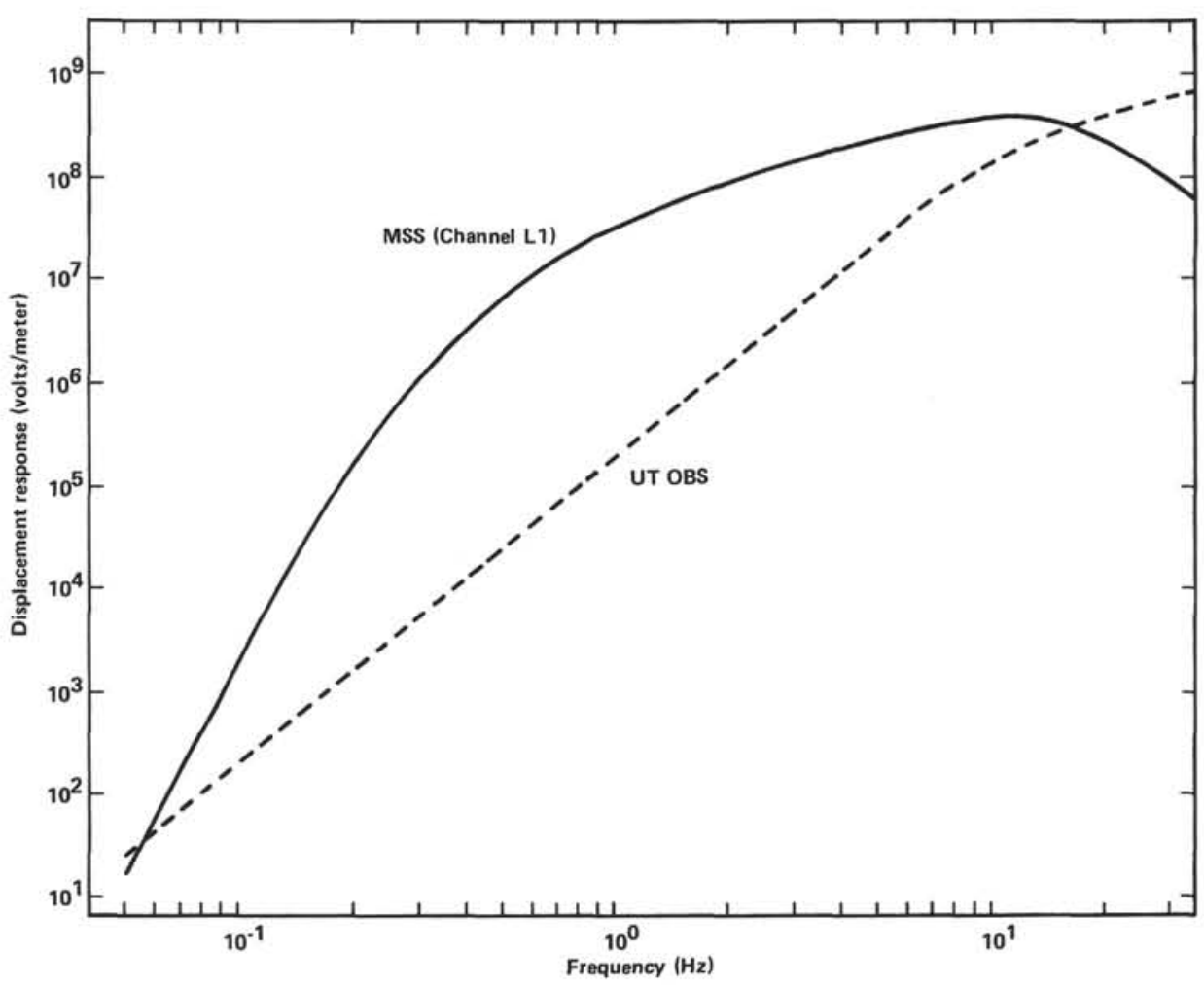

Figure 3. Displacement responses of Leg 78B seismic systems. The MSS employed two vertical-component, short-period, force-feedback, piezoelectric seismometers (Teledyne Geotech model S-700') whose outputs were filtered to prevent aliasing and then digitized at 75 samples/s. The MSS response is peaked near $11 \mathrm{~Hz}$, and falls off at $12 \mathrm{~dB}$ /octave toward lower frequencies and at $15 \mathrm{~dB} /$ octave to the Nyquist frequency. The University of Texas (UT) ocean-bottom seismometer system consisted of a triaxial set of critically damped, 10- Hz Mark L6 geophones whose outputs were sampled with an 8.352-ms digitizing interval. The UT OBS response increases with frequency at $18 \mathrm{~dB} /$ octave up to $10 \mathrm{~Hz}$, and at $6 \mathrm{~dB} /$ octave thereafter.

mated from the data collected by Scripps Institution of Oceanography OBSs suggest that noise caused by nearby ships is significant only above approximately $5 \mathrm{~Hz}$ and is typically manifested as sharp peaks at a few frequencies and several of their higher harmonics. The high noise levels above $10 \mathrm{~Hz}$ on the UT OBS may be attributed, at least in part, to ship noise amplified by frame resonances.

Another possible noise source is the flow of water past the instruments (Duennebier et al., 1981). This noise is thought to be generated when current speeds are in excess of $10 \mathrm{~cm} / \mathrm{s}$, but there is a complex dependence on body geometry. In the simple case of a cylinder, the frequency of the noise is inversely proportional to the diameter; the whip antenna on the OBS would have a flow-noise frequency of about $6 \mathrm{~Hz}$ for a current speed of $10 \mathrm{~cm} / \mathrm{s}$. Near-bottom current measurements $(5 \mathrm{~m}$ above the seafloor) were made approximately $4 \mathrm{~km}$ north of the UT OBS during the period $28 \mathrm{March}-1$ April (Boyd, this volume). The average current speed was $4.4 \mathrm{~cm} / \mathrm{s}$ and the maximum was $8.9 \mathrm{~cm} / \mathrm{s}$, so it is likely that current noise is not significant for the OBS noise observations. In the case of the MSS, temperature logs indicate that water was flowing down the hole at a rate of $25 \mathrm{~m}$ / $\mathrm{hr}$. but disappeared into the basement within the upper $500 \mathrm{~m}$ of the hole, $100 \mathrm{~m}$ above the borehole instrument package (Becker et al., this volume). Also, there was no evidence for hydrothermal circulation anywhere in the hole. Water flow is not, therefore, a significant contribution to noise levels observed on the MSS. We feel the MSS data reliably represent intrinsic earth noise in the band 0.16 to $2.2 \mathrm{~Hz}$; the OBS data probably do so between 0.18 and $4 \mathrm{~Hz}$.

\section{DISCUSSION}

Although the stability of the noise estimates computed from $44 \mathrm{~min}$. of MSS data implies that the microseismic noise was quasistationary on the time scale of $1 \mathrm{hr}$., the recorded amplitudes increased enough over one day to cause clipping on the channel of highest usable gain (L1). On the time scale of $10 \mathrm{hrs}$., the power densities, computed from channel U2 data, were stable in shape but increased by up to $5 \mathrm{~dB}$ (Fig. 10). Displacement spectra were peaked between 0.2 and $0.3 \mathrm{~Hz}$, and decreased with frequency at $80 \mathrm{~dB} /$ decade. The earliest of the spectra in Figure 10 had a peak value of $4 \times 10^{6}$ $\mathrm{nm}^{2} / \mathrm{Hz}$ at $0.21 \mathrm{~Hz}$, and fell from $1 \times 10^{6} \mathrm{~nm}^{2} / \mathrm{Hz}$ at $0.33 \mathrm{~Hz}$ to $1 \mathrm{~nm}^{2} / \mathrm{Hz}$ at $1.9 \mathrm{~Hz}$. A more detailed study of the temporal noise variation was conducted using integrated, uncorrected power densities from channel U2 (which was not clipped by noise) as a measure of level (Fig. 11A). The power densities were computed from 


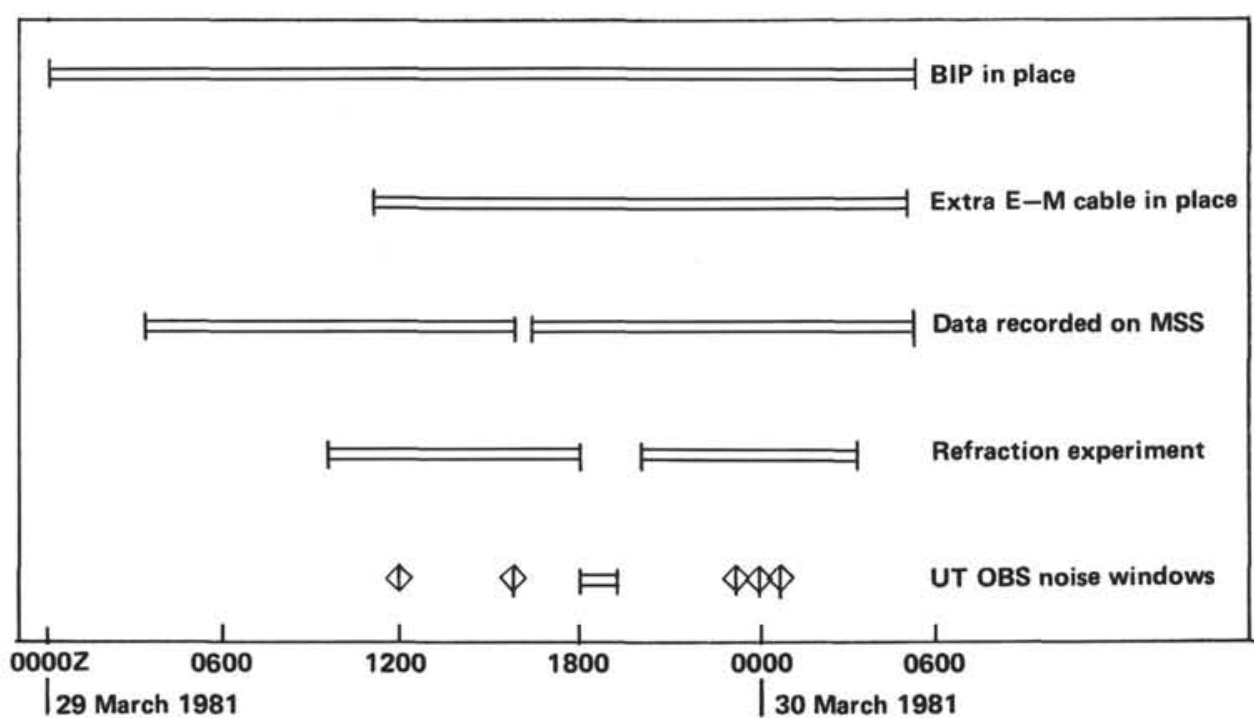

Figure 4. Times of important operations and events during the Leg 78B noise experiment. The borehole instrument package (BIP) first entered Hole 395A at 0257Z, 28 March 1981, but was not in place for the refraction and noise experiments until $0000 \mathrm{Z}, 29$ March. The BIP was recovered at $0512 \mathrm{Z}, 30$ March. The BIP was not clamped in the hole, but was isolated from ship motions by $0.7 \mathrm{~km}$ of electromechanical (E-M) cable payed out on the seafloor at 1100Z, 29 March. Twenty-six hrs. of data were recorded continuously by the MSS, except for a 35-min. gap beginning at $0545 \mathrm{Z}, 29 \mathrm{March}$. The refraction experiment began at $0925 \mathrm{Z}, 29 \mathrm{March}$, ended at $0220 \mathrm{Z}, 30 \mathrm{March}$, and was broken by a 2-hr. hiatus between 1800 and $2000 \mathrm{Z}, 29 \mathrm{March}$, during which the noise experiment was performed. The University of Texas ocean-bottom seismograph (UT OBS) recorded eleven 34-s noise samples, six during the noise experiment. The remaining five, denoted by diamonds, correspond to windows when refraction shots failed to explode.

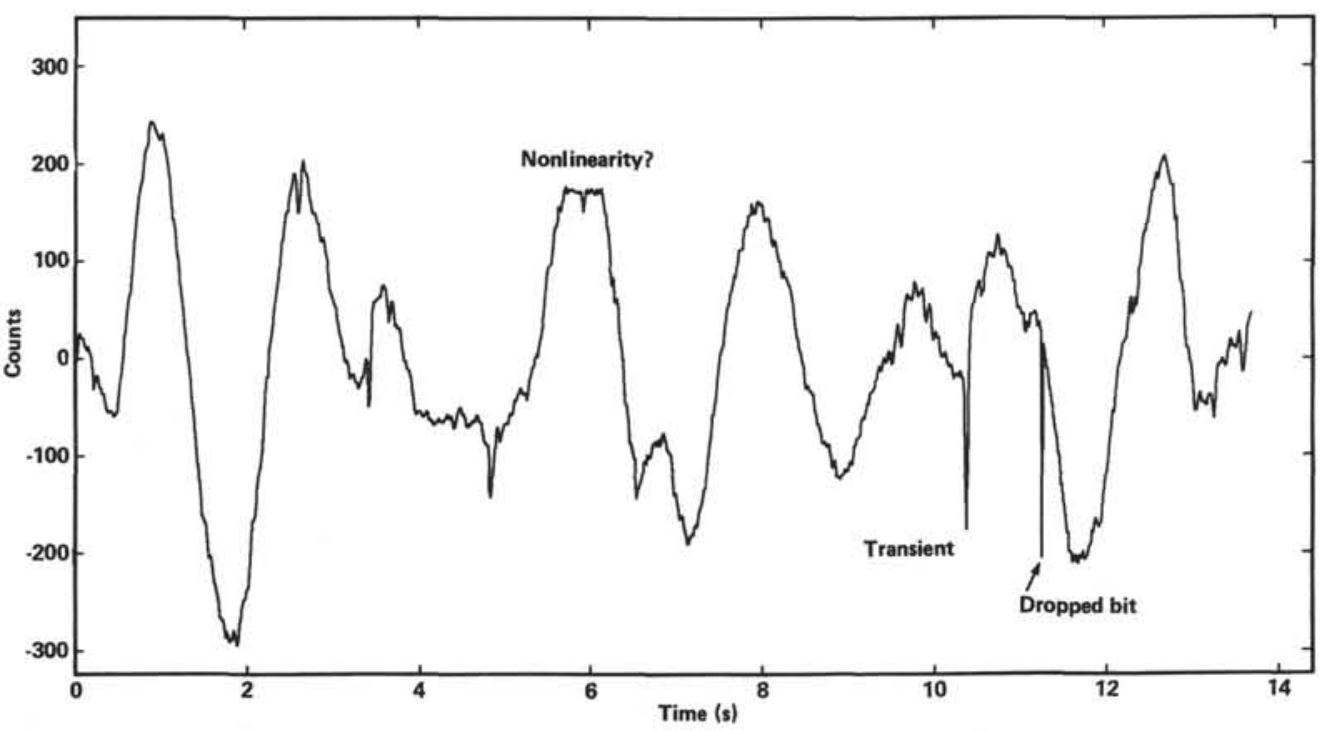

Figure 5. Record sample from channel L1, illustrating characteristics of MSS noise data. Low-frequency $(0.2-0.3 \mathrm{~Hz})$ energy dominates the time series. Features typical of those which contribute to noise are the dropped bit near $11 \mathrm{~s}$; the frequent, random, unidirectional transients, such as the one labeled near $10.5 \mathrm{~s}$; and the truncated low-frequency peak centered at $6 \mathrm{~s}$. The last may result from an instrument nonlinearity. Units are digital counts, and positive amplitude corresponds to upward mass movement.

$13.65 \mathrm{~s}$ of data sampled at approximately 15 -min. intervals and smoothed with a three-point running mean. A trend of increasing noise levels is clearly discernible. This variability of ocean-bottom noise may be caused by changes in local sea state and/or weather (Latham and Sutton, 1966; Latham and Nowroozi, 1968). As can be seen in Figure 11B, bihourly observations of swell height recorded on the Challenger's deck log strongly correlated with the noise level. The (nonlinear) interaction between opposing swell produces significant pressure fluctuations on the seafloor at half the swell period (Longuet-Higgins, 1950; Kadota and Labianca, 1981), and indeed, the reported swell period of 10 to $11 \mathrm{~s}$ is approximately twice that of the spectral peak between 3 


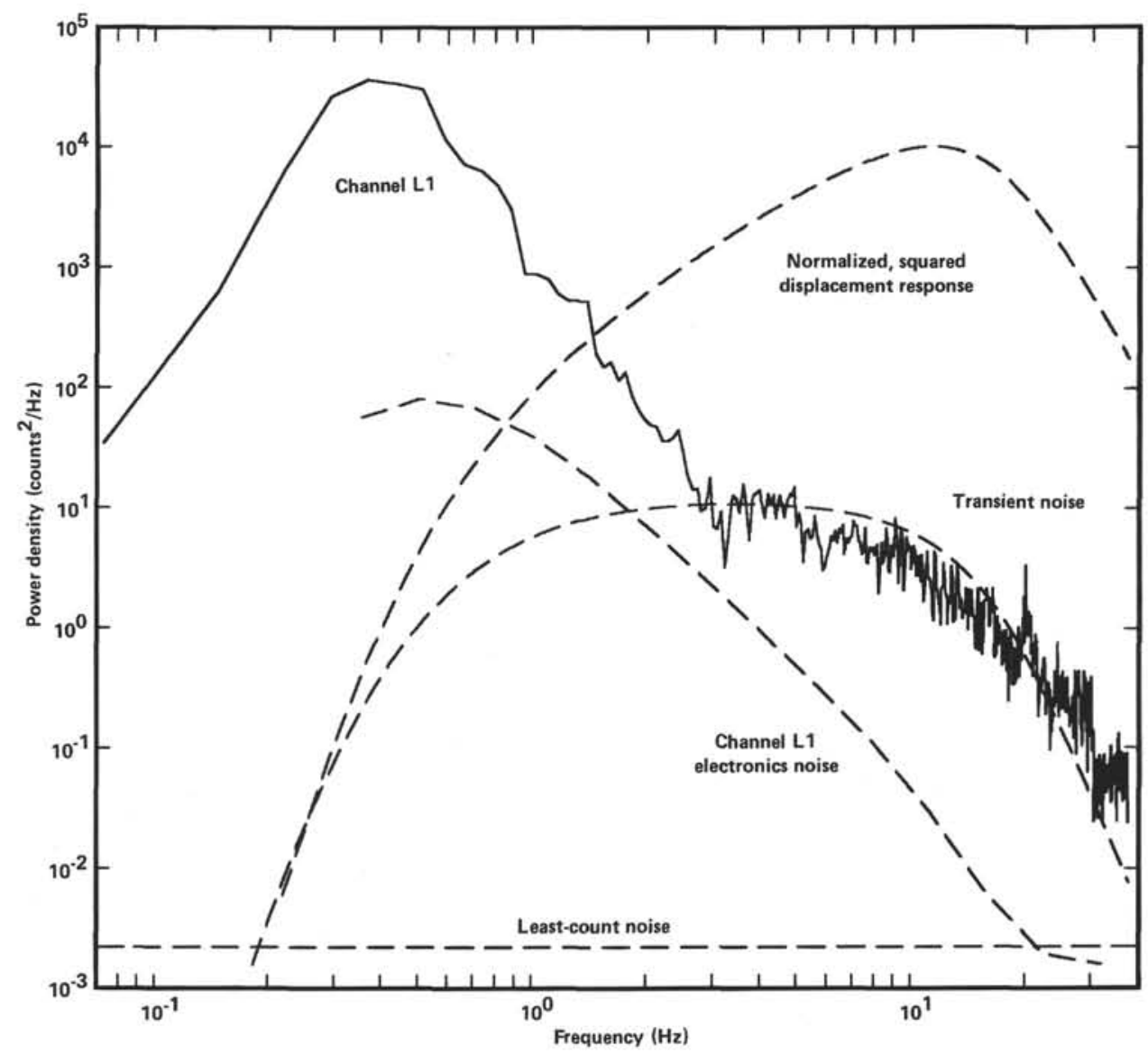

Figure 6. Power spectral densities of MSS data compared with estimates of instrument noise. The data (solid line) were computed from eight 13.65-s samples from channel L1, with no instrument correction applied. The electronics noise was estimated from RMS power values of $1 / 2$-octave bandwidth provided by Teledyne Geotech. The least-count noise level is that expected from uniformly distributed errors owing to the representation of a continuous quantity by a finite digital word. The transient-noise spectrum, which is attributed to the frequent, impulsive features identified in Figure 5, was computed from equation A24 (see Appendix), and defines the high-frequency limit of reliable microseismic noise estimates. Also shown in this figure is the squared, normalized MSS displacement response.

and $5 \mathrm{~s}$ (Fig. 10). A more definite conclusion is not justified, however, by the limited data set used here. The period of the noise peak is within the range of the socalled "microseism peak" observed at the ocean bottom (Latham and Sutton, 1966; Latham and Nowroozi, 1968) and on continents (Melton, 1976), where, in the latter instance, there is ample evidence ascribing the microseism peak to the nonlinear swell interaction (Haubrich et al., 1963; Haubrich and McCamy, 1969).

The detailed, temporal behavior of noise at the seafloor during the MSS deployment cannot be reliably determined because of the paucity of appropriate OBS data. However, simultaneous noise observations were made by the two seismic systems on eleven occasions, nine of which may be used for comparison (Fig. 4). Six of these were recorded over a 75-min. period scheduled specifically for noise studies, and afford stable, high-resolution spectral estimates (Fig. 12). In the band of overlap $(0.18-2 \mathrm{~Hz})$, noise levels were higher at the seafloor than in the borehole by an amount which increased with frequency from $10 \mathrm{~dB}$ at $0.2 \mathrm{~Hz}$ to $28 \mathrm{~dB}$ at $2.2 \mathrm{~Hz}$. This is consistent with the notion that, at these frequencies, mi- croseismic noise propagates primarily as fundamentalmode Stoneley waves (Latham and Sutton, 1966; Latham and Nowroozi, 1968; Bradner and Dodds, 1964; Bradner et al., 1965; Tuthill et al., 1981). A large acoustic-wave/shear-wave impedance mismatch at a fluid/solid interface results in the severe exponential decay of this wave away from the interface, essentially trapping the seismic energy (Latham and Sutton, 1966; Tuthill et al., 1981). Site 395 is in a ponded depression amid rugged bathymetric relief (Fig. 1), which may affect seismic amplitudes in complex ways; but if the sediments are the dominating influence at this site, Stoneley-wave amplitudes at frequencies above the frequency of the microseismic peak should be significantly lower below the base of the sediments than at the seafloor.

The remaining five noise windows were widely spaced in time and were intended to be for explosion signals, but the shots failed to detonate; only three may be used for comparison, because of excessive instrument noise on the MSS. Seafloor noise levels were 10 to $30 \mathrm{~dB}$ higher than in the borehole for these samples as well. (The power densities shown in Fig. 13 were of similar resolu- 


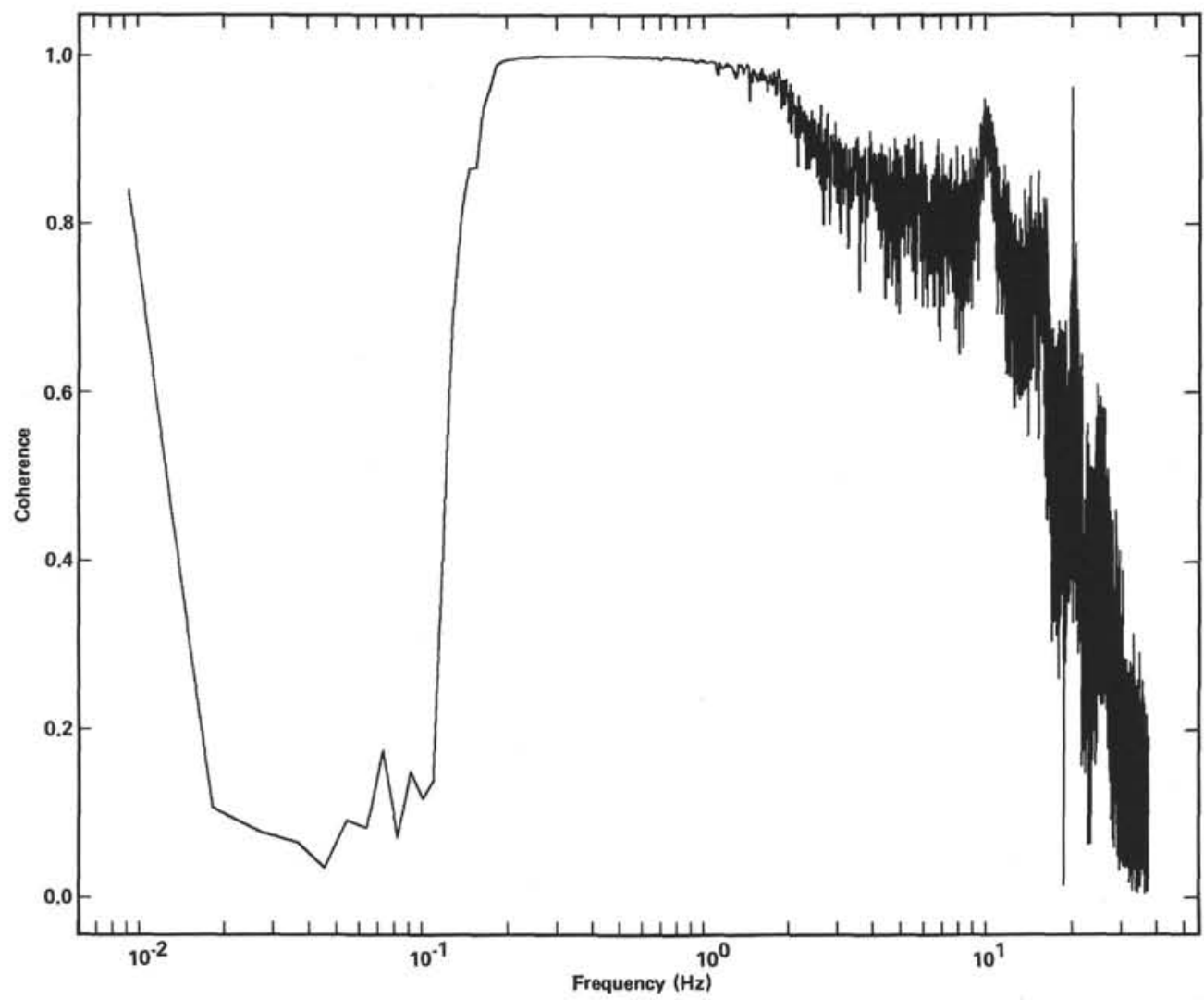

Figure 7. Coherence between the highest-usable-gain channels of each of the MSS seismometers (L1 and U2). The coherence spectrum was computed from twenty-four 109.2-s samples from each channel. The energy is highly incoherent below $0.16 \mathrm{~Hz}$, where response roll-off causes instrument noise to dominate.

tion and variance: the MSS data were eight 6.83-s samples, and the UT OBS data were eight 4.28-s samples.)

Representative extrema of microseismic noise levels observed during the ten years of the Scripps Institution of Oceanography's OBS program are compared in Figure 14 with the lowest reliable levels observed during Leg 78B. The SIO OBSs employed $1-\mathrm{Hz}$ digitally recorded seismometers (Prothero, 1974; Moore et al., 1981). Power densities were computed from the vertical-component output, which resided in semiconductor memory before being buffered to tape, and thus were not contaminated by the mechanical tape-recorder noise. Data for the "noisiest site" were fifty-one 8-s samples collected southeast of Hawaii, and those for the "quietest site" were thirtyfour 4-s samples collected on the East Pacific Rise near $20^{\circ} \mathrm{N}$. The extrema are separated by 20 to $30 \mathrm{~dB}$. The UT OBS values are similar to the SIO OBS maxima; the MSS values are intermediate to low.

Continental noise observations are compared with the MSS spectrum in Figure 15. The Queen Creek data were recorded in a mine in Queen Creek, Arizona (Melton, 1976; Fix, 1972), and the Lajitas data were recorded at a site near Lajitas, Texas (Herrin, 1982). The Brune-Oliver curves represent average and high levels for continental stations, and were taken from Melton (1976), who reanalyzed Brune and Oliver's (1959) summary of published noise observations. MSS levels are 35 to $40 \mathrm{~dB}$ greater than the exceptionally low Queen Creek and Lajitas values, and fall between the Brune-Oliver curves.

\section{CONCLUSIONS}

The noise levels detected by the MSS in Hole 595A, approximately $600 \mathrm{~m}$ below the sediment/water interface, were 10 to $30 \mathrm{~dB}$ lower than those recorded by the University of Texas OBS over the frequency range 0.2 to $2.0 \mathrm{~Hz}$ (Figs. 12 and 13). This observation is consistent with the hypothesis that seismic noise at these frequencies propagates primarily as low-order Stoneley modes trapped at the seafloor interface (Bradner et al., 1965; Latham and Sutton, 1966; Latham and Nowroozi, 1968; Tuthill et al., 1981). The correlation of the noise levels with swell heights (Fig. 11) suggests that the generation of seafloor noise at this mid-Atlantic site is dominated by local nonlinear ocean-wave interactions. To within the accuracy of the deck-log observations, the swell period was approximately twice that of the microseismic noise peak, consistent with the Longuet-Higgins mechanism and previous ocean-bottom measurements (Latham and Nowroozi, 1968).

Seafloor noise levels at Site 395 were comparable to the highest values yet recorded by Scripps OBSs in the Pacific (Fig. 14), so, even with the reduction achieved by placing the sensor down a borehole, the MSS noise levels are on the order of $30 \mathrm{~dB}$ greater than these obtained 


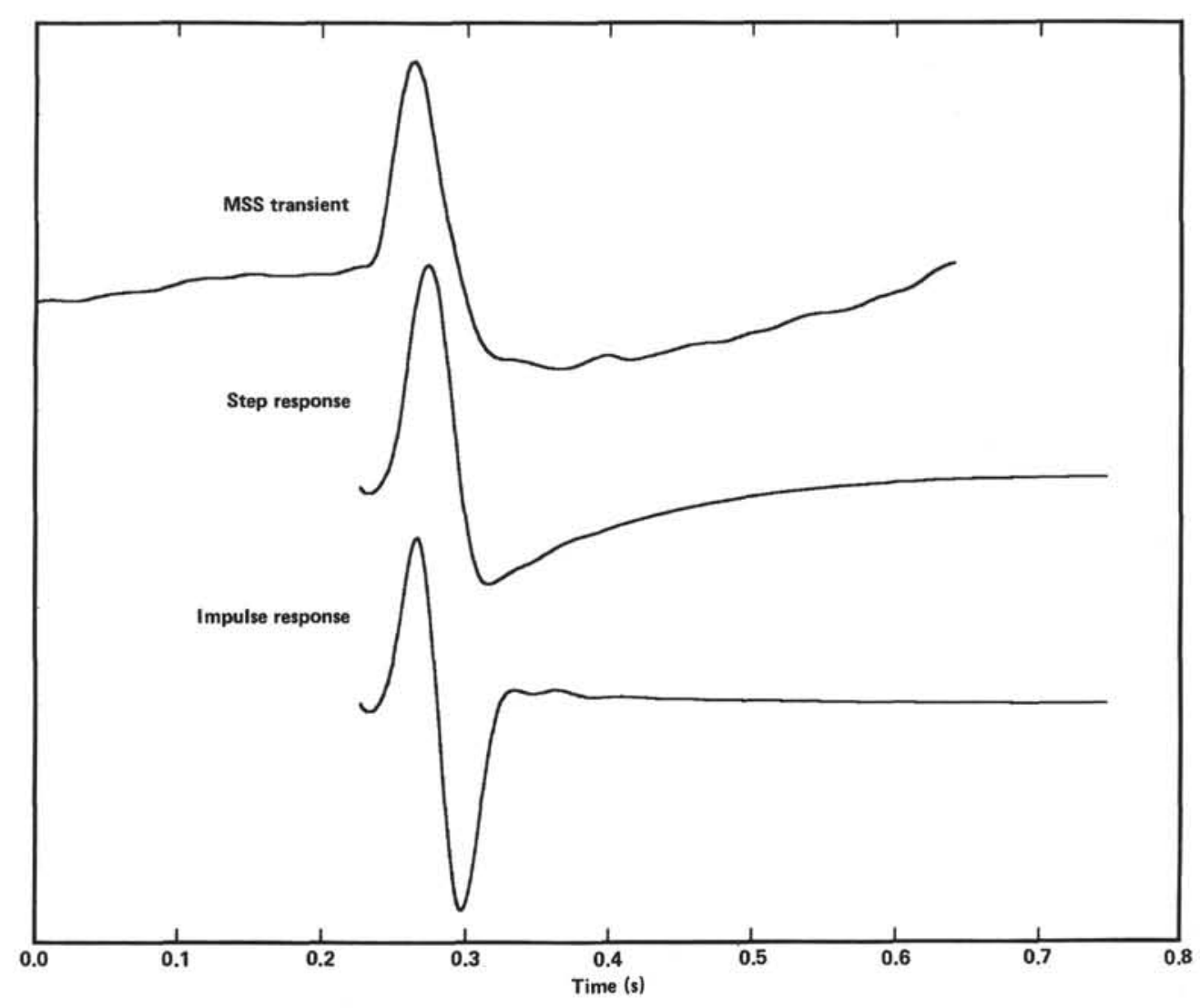

Figure 8. Transient shape compared with the MSS responses to a step and to an impulse in displacement. The transients observed in the MSS data resemble the step responses more closely than the impulse responses, and are taken as such for the purpose of computing the transient-noise spectrum shown in Figure 6.

at quiet continental sites (Fig. 15). If the relationship between seafloor and sub-bottom noise spectra in Figure 14 is maintained at quieter locations, however, then the noise levels may be reduced substantially downhole, and could compare favorably with typical continental sites.

Future deployments of the MSS are planned using a triaxial set of seismometers and a long-term ocean-bottom recording package. Such a system, complemented by an array of OBSs, should be able to answer definitively questions concerning the mode and generation mechanism of microseismic noise in the deep ocean.

\section{ACKNOWLEDGMENTS}

The authors thank Teledyne Geotech and the University of Texas for making available the data used in the noise analysis. In particular, Carl Mulcahy of Teledyne Geotech is to be thanked for his firsthand knowledge of the MSS and for his tireless assistance. Bill O'Brien was helpful with details of the OBS deployment.

\section{REFERENCES}

Bradner, H., and Dodds, J. G., 1964. Comparative seismic noise on the ocean bottom and on land. J. Geophys. Res., 69:4339-4348.

Bradner, H., Dodds, J. G., and Foulks, R. E., 1965. Investigation of microseism sources with ocean-bottom seismometers. Geophysics, 30:511-526.

Brune, J. N., and Oliver, J., 1959. The seismic noise of the Earth's surface. Seismol. Soc. Am. Bull., 49:349-353.

Darbyshire, J., 1960. Microseisms. In Hill, M. N. (Ed.), The Sea (Vol. 1): New York (Wiley-Interscience), 700-719.

Duennebier, F. K., Blackinton, G., and Sutton, G. H., 1981. Currentgenerated noise recorded on ocean bottom seismometers. Mar. Geophys. Res., 5:109-115.
Fix, J. E., 1972. Ambient Earth motion in the period range from 0.1 to 2560 s. Seismol. Soc. Am. Bull., 62:1753-1760.

Haubrich, R. A., and McCamy, K., 1969. Microseisms: coastal and pelagic sources. Rev. Geophys., 7:539-571.

Haubrich, R. A., Munk, W. H., and Snodgrass, F. E., 1963. Comparative spectra of microseisms and swell. Seismol. Soc. Am. Bull., 53:27-37.

Herrin, E., 1982. Seismic instruments used in treaty verification. Seismol. Soc. Am. Bull., 72:S61-S67.

Kadota, T. T., and Labianca, F. M., 1981. Gravity-wave-induced pressure fluctuations in the deep ocean. IEEE J. Oceanic Eng., OE-6: 50-58.

Latham, G. V., and Sutton, G. H., 1966. Seismic measurement on the ocean floor. 1. Bermuda area. J. Geophys. Res., 71:2545-2573.

Latham, G. V., and Nowroozi, A. A., 1968. Waves, weather, and ocean bottom microseisms. J. Geophys. Res., 73:3945-3956.

Longuet-Higgins, M., 1950. A theory of the origin of microseism. Phil. Trans. Roy. Soc. London, A243:1-35.

Melton, B. S., 1976. The sensitivity and dynamic range of inertial seismographs. Rev. Geophys. Space Phys., 14:93-116.

Moore, R. D., Dorman, L. M., Huang, C.-Y., and Berliner, D. L., 1981. An ocean bottom, microprocessor based seismometer. Mar. Geophys. Res., 4:451-477.

Otnes, R. K., and Enochson, L., 1982. Digital Time Series Analysis: New York (John Wiley).

Prentiss, D. D., and Ewing, J. I., 1963. The seismic motion of the deep ocean floor. Seismol. Soc. Am. Bull., 53:765-781.

Prothero, W. A., 1974. Ocean bottom seismomete capsule. Seismol. Soc. Am. Bull., 64:1251-1262.

Rice, S. O., 1944-1945. Mathematical analysis of random noise. Bell Sys. Tech. J., Vol. 23-24. Also in Wax, N. (Ed.), 1954. Selected Papers on Noise and Stochastic Processes: New York (Dover).

Schneider, W. A., and Backus, M. M., 1964. Ocean bottom seismic measurements off the California coast. J. Geophys. Res., 69: $1135-1143$. 
Schneider, W. A., Farrell, P. J., and Brannian, R. E., 1964. Collection and analysis of Pacific ocean-bottom seismic data. Geophysics, 29: 745-771.

Stephen, R. A., Johnson, S., and Lewis, B., 1983. The oblique seismic experiment on Deep Sea Drilling Project Leg 65. In Lewis, B. T. R., Robinson, P., et al., Init. Repts. DSDP, 65: Washington (U.S. Govt. Printing Office), 319-327.

Stephen, R. A., Louden, K. E., and Matthews, D. H., 1980. The oblique seismic experiment on Deep Sea Drilling Project Leg 52. In Donnelly, T., Francheteau, J., Bryan, W., Robinson, P., Flower, M., Salisbury, M., et al., Init. Repts. DSDP, 51, 52, 53, Pt. 1: Washington (U.S. Govt. Printing Office), 675-704.

Tuthill, J. D., Lewis, B. T. R., and Garmany, J. D., 1981. Stoneley waves, Lopez Island noise, and deep sea noise from 1 to $5 \mathrm{~Hz}$. Mar. Geophys. Res., 5:95-108.

Welch, P. D., 1967. The use of fast Fourier transform for the estimation of power spectra: A method based on time averaging over short, modified periodograms. IEEE Trans. Audio Electro-Acoust., AU-15:70-73.

Date of Initial Receipt: January 12, 1983

Date of Acceptance: July 29, 1983

\section{APPENDIX}

In this appendix we model the transient noise observed in the MSS data as a compound, stationary Poisson process (Feller, 1968), and derive an expresson for its power spectral density function for the time interval $0 \leq t \leq T$. We define the process

$$
S_{N}(t)=\sum_{k=1}^{N} X_{k}(t)
$$

where $\left\{X_{k}\right\}$ is a sequence of identically distributed, independent, stochastic variables, and $N$ has a stationary Poisson probability distribution

$$
P(N=n)=\frac{e^{-\lambda T}(\lambda T)^{n}}{n !}
$$

The expected value of $N$ is

$$
\begin{aligned}
\langle N\rangle & =\sum_{n=0}^{\infty} n P(N=n) \\
& =\lambda T
\end{aligned}
$$

so that the constant $\lambda$ may be interpreted as the mean rate of event occurrence.

The $\left\{X_{k}\right\}$ are assumed to have the form

$$
X_{k}(t)=\alpha_{k} h\left(t-t_{k}\right)
$$

where $h(t)$ is the transient shape and $\left\{\alpha_{k}\right\}$ and $\left\{t_{k}\right\}$ are the transient amplitude and occurrence times, respectively. $N,\left\{\alpha_{k}\right\}$, and $\left\{t_{k}\right\}$ are assumed to be mutually independent random variables; in particular, the $\left\{t_{k}\right\}$ are assumed to be uniformly distributed over the time of observation, $T$.

We wish to find the power spectral density function $P_{S}(f)$ of $S_{N}(t)$ at frequency $f . P_{S}$ is the Fourier transform of the autocovariance function $R_{S S}(\tau)$ of $S_{N}$ :

$$
P_{S}(f)=2 \int_{-\infty}^{\infty} R_{S S}(\tau) e^{-i 2 \pi f \tau} d \tau
$$

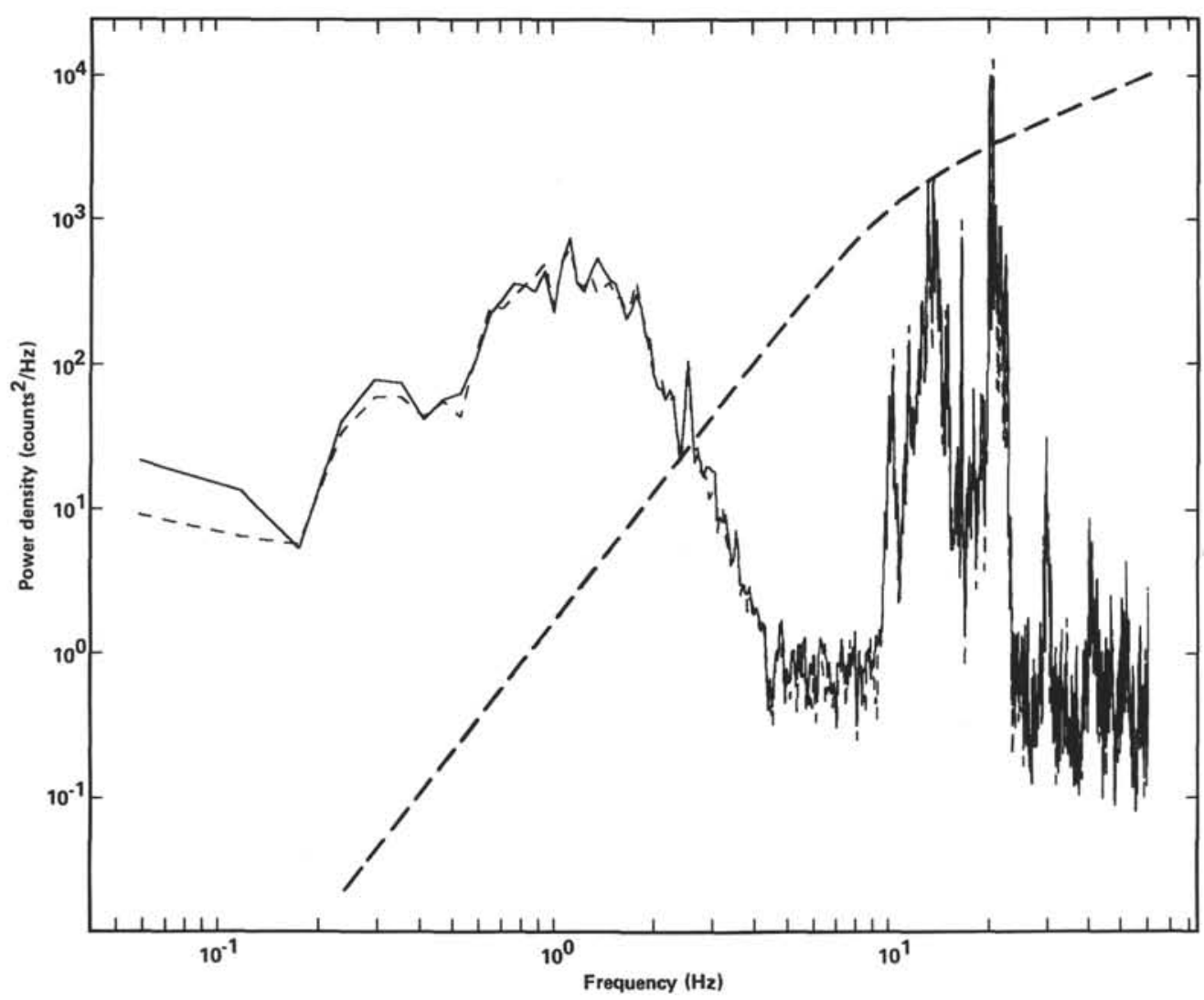

Figure 9. Uncorrected UT OBS power densities. Spectra were computed from eleven 17.1-s segments obtained from six 34.2-s noise samples recorded over a 75-min. period. The large amplitudes between 10 and $25 \mathrm{~Hz}$ may be the result of resonance of the OBS frame, and the flat portions above $4 \mathrm{~Hz}$ and below $0.18 \mathrm{~Hz}$ are probably imposed by instrument noise. Spectra between 0.18 and $4 \mathrm{~Hz}$ are thought to estimate reliably the ambient noise levels on the seafloor. 


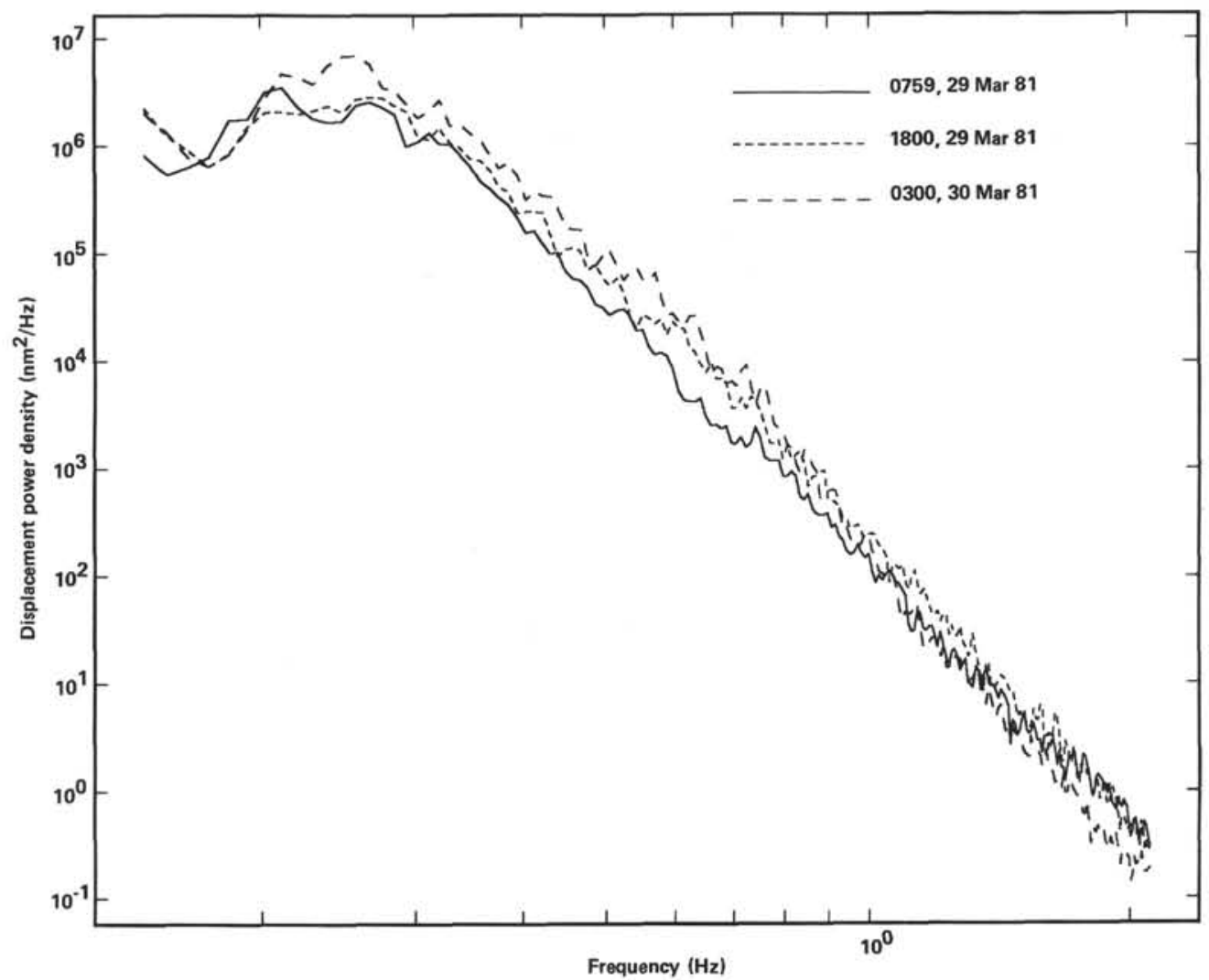

Figure 10. Displacement power densities (in $\mathrm{nm}^{2} / \mathrm{Hz}$ ) in Hole $395 \mathrm{~A}$ at approximately 10-hr. intervals. Each curve was computed from twenty-four 109.2-s samples from channel U2. The spectral shape of the noise was stable over this period, but amplitudes increased with time. Power densities fall at approximately $80 \mathrm{~dB} /$ decade beyond the peak at $0.2-0.3 \mathrm{~Hz}(24 \times 8192$ points; corrected Channel U2).

$$
R_{S S}(\tau)=\left\langle\left[S_{N}(t)-\left\langle S_{N}(t)\right\rangle\right]\left[S_{N}(t+\tau)-\left\langle S_{N}(t+\tau)\right\rangle\right]\right\rangle
$$

The factor of 2 in equation A6 is consequent to our normalization of $P_{S}(f)$, in which the total power per Nyquist bandwidth is equal to the variance of the time signal (the energy of the negative frequencies is folded into the positive).

Note that since $S_{N}$ is stationary, $\left\langle S_{N}(t)\right\rangle$ is independent of $t$, and equation $\mathrm{A} 7$ is equivalent to

$$
R_{S S}(\tau)=\left\langle S_{N}(t) S_{N}(t+\tau)\right\rangle-\left\langle S_{N}\right\rangle^{2}
$$

We will evaluate the two terms of this equation separately. The mean value of $S_{N}$ is

$$
\left\langle S_{N}\right\rangle=\sum_{n=0}^{\infty} P(N=n)\left\langle\sum_{k=1}^{n} X_{k}\right\rangle=\sum_{n=0}^{\infty} P(N=n) n\left\langle X_{k}\right\rangle
$$

Since $N,\left\{\alpha_{k}\right\}$, and $\left\{t_{k}\right\}$ are mutually independent,

$$
\left\langle S_{k}\right\rangle=\langle N\rangle\left\langle X_{k}\right\rangle
$$

where for each $X_{k}$,

$$
\left\langle X_{k}\right\rangle=\left\langle\alpha_{k} h\left(t-t_{k}\right)\right\rangle=\langle\alpha\rangle \frac{1}{T} \int_{0}^{T} h\left(t-t_{k}\right) d t_{k}
$$

in which we have used the assumption that the $\left\{\alpha_{k}\right\}$ are identically distributed and therefore have the same mean $\langle\alpha\rangle$. We assume that the interval of observation $T$ is much larger than the transient duration, so that, approximately,

$$
\left\langle X_{k}\right\rangle=\langle\alpha\rangle \frac{1}{T} \int_{0}^{\infty} h(t) d t \equiv\langle X\rangle
$$

and thus, using equation A4,

$$
\left\langle S_{N}\right\rangle=\lambda\langle\alpha\rangle \int_{0}^{\infty} h(t) d t \equiv\langle S\rangle
$$

We now consider the bivariate moment in equation A8:

$$
\begin{aligned}
& \left\langle S_{N}(t) S_{N}(t+\tau)\right\rangle \\
& =\sum_{n=0}^{\infty} P(N=n)\left\langle\sum_{k=1}^{n} X_{k}(t) \sum_{m=1}^{n} X_{m}(t+\tau)\right\rangle
\end{aligned}
$$

The mutual independence of the $\left\{X_{k}\right\}$ implies

$$
\begin{aligned}
\left\langle\sum_{k=1}^{n} X_{k}(t) \sum_{m=1}^{n} X_{m}(t-\tau)\right\rangle & =n\left\langle X_{k}(t) X_{k}(t+\tau)\right\rangle \\
& +n(n-1)\langle X\rangle^{2}
\end{aligned}
$$

The bivariate moment of $X_{k}$ at lag $\tau$ is

$$
\left\langle X_{k}(t) X_{k}(t+\tau)\right\rangle=\left\langle\left[\alpha_{k} h\left(t-t_{k}\right)\right]\left[\alpha_{k} h\left(t-t_{k}+\tau\right)\right]\right\rangle
$$


A

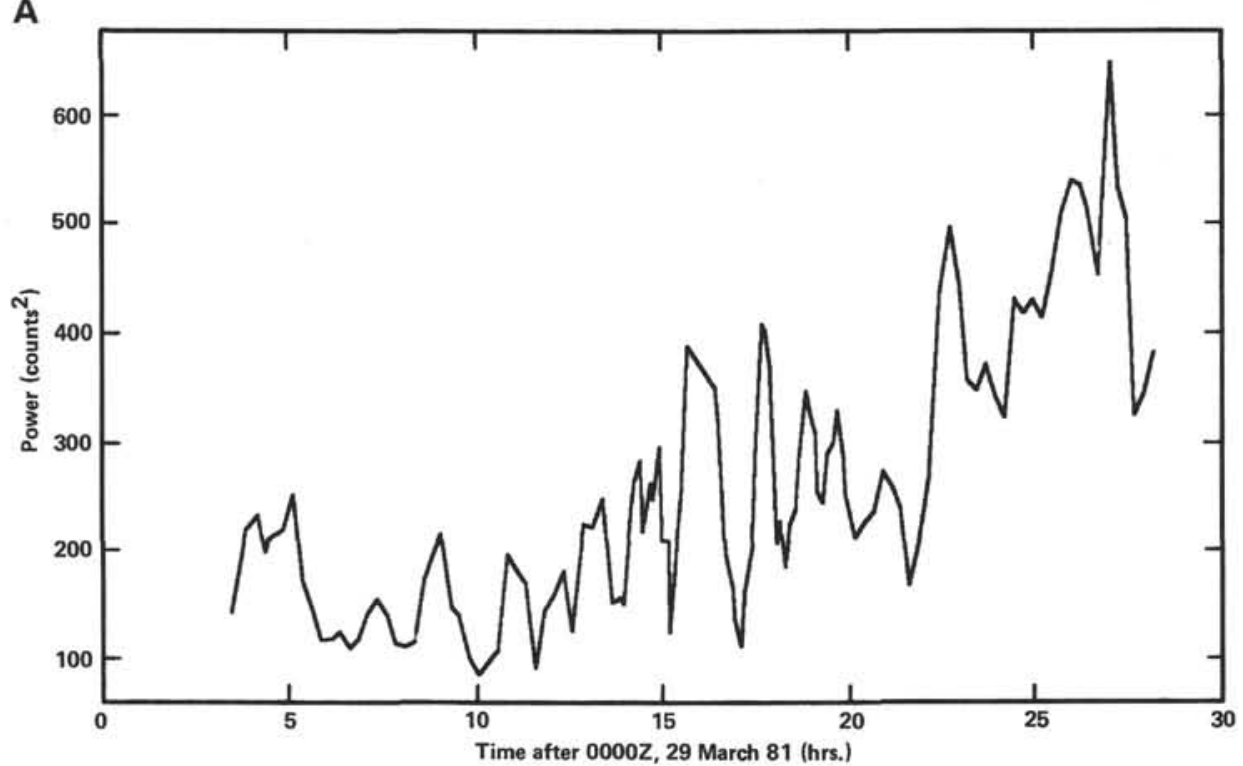

B

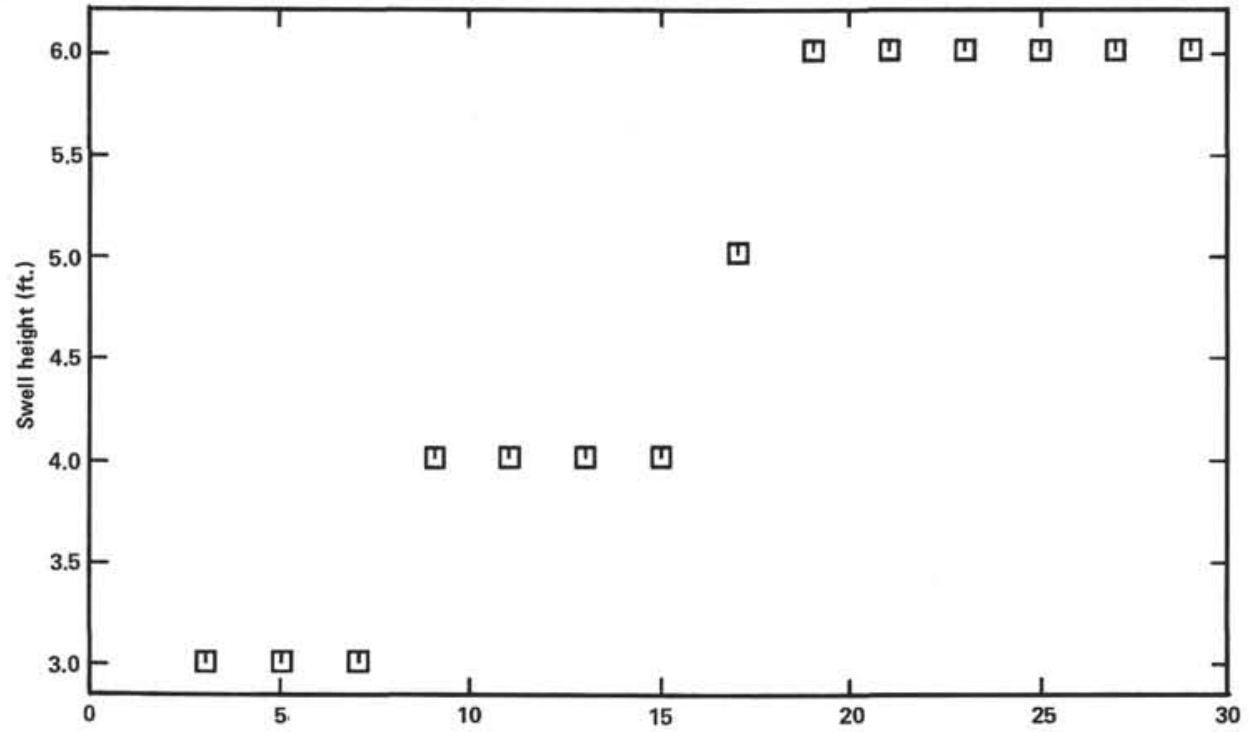

Figure 11. Temporal variations of (A) borehole noise levels and (B) local swell height. The noise level was estimated from integrated, smoothed power densities computed from $13.65 \mathrm{~s}$ of uncorrected channel U2 data sampled at approximately 15 -min. intervals. A three-point running mean was applied to the integrated values. The swell height was recorded bihourly on the Challenger's deck log.

$$
\begin{aligned}
& =\left\langle\alpha^{2}\right\rangle \frac{1}{T} \int_{t_{k}}^{T} h\left(t^{\prime}\right) h\left(t^{\prime}+\tau\right) d t^{\prime} \\
& \approx\left\langle\alpha^{2}\right\rangle \frac{1}{T} h * h(\tau)
\end{aligned}
$$

where "*" denotes cross-correlation. Collecting these results,

$$
\begin{aligned}
\left\langle S_{N}(t) S_{N}(t+\tau)\right\rangle & =\langle N\rangle\left\langle\alpha^{2}\right\rangle \frac{1}{T} h * h(\tau) \\
& +\langle N(N-1)\rangle\langle X\rangle^{2}
\end{aligned}
$$

From equation $\mathrm{A} 2$ we find that

$$
\langle N(N-1)\rangle=(\lambda T)^{2}
$$

Thus, from equations A12 and A13,

$$
\left\langle S_{N}(t) S_{N}(t+\tau)\right\rangle=\lambda\left\langle\alpha^{2}\right\rangle h * h(\tau)+\langle S\rangle^{2}
$$

so, finally,

$$
R_{S S}(\tau)=\lambda\left\langle\alpha^{2}\right\rangle h * h(\tau)
$$

It is now a simple matter to determine $P_{S}(f)$ using equations $A 7$ and A22. A well-known result from Fourier analysis (Bracewell, 1965) is that 
R. G. ADAIR, J. A. ORCUTT, T. H. JORDAN

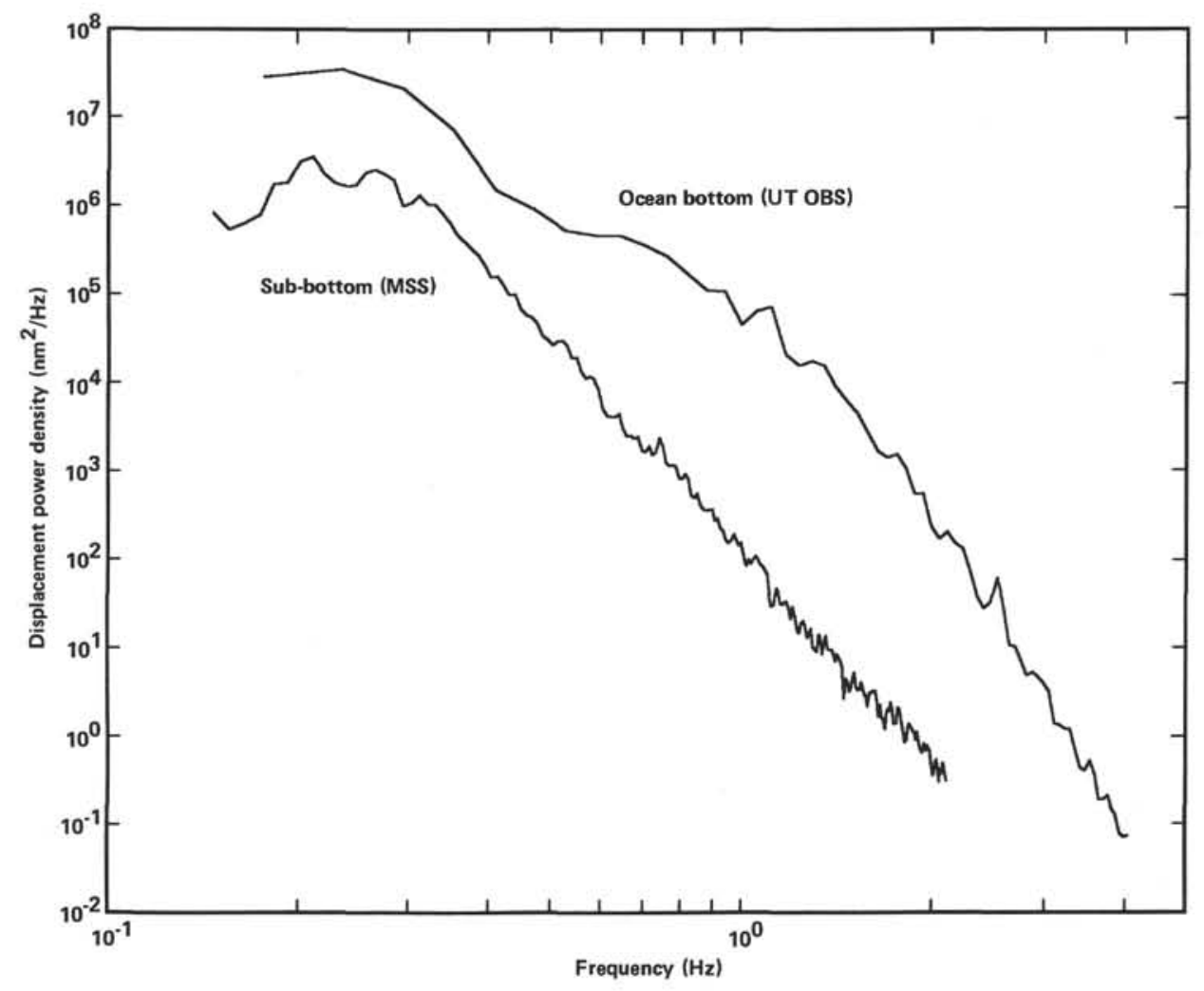

Figure 12. Comparison of ambient seismic noise at and below the seafloor near Hole 395A, using corrected UT OBS and MSS data recorded during the period 1800 to $1900 \mathrm{Z}, 29 \mathrm{March} 1981$. The UT OBS data were six 34.2-s samples, and the MSS data were six 109.2-s samples; the former were broken into eleven 17.1-s segments, the latter into eleven of 54.6-s duration.

$$
\int_{0}^{\infty} h * h(\tau) e^{-i 2 \pi f \tau} d \tau=|H(f)|^{2}
$$

where $H(f)$ is the Fourier transform of $h(t)$. Hence,

$$
P_{S}(f)=2 \lambda\left\langle\alpha^{2}\right\rangle|H(f)|^{2}
$$

\section{REFERENCES}

Bracewell, R., 1965. The Fourier Transform and Its Application: New York (NcGraw-Hill).

Feller, W., 1968. An Introduction to Probability Theory and Its Application (Vol. I): New York (John Wiley). 


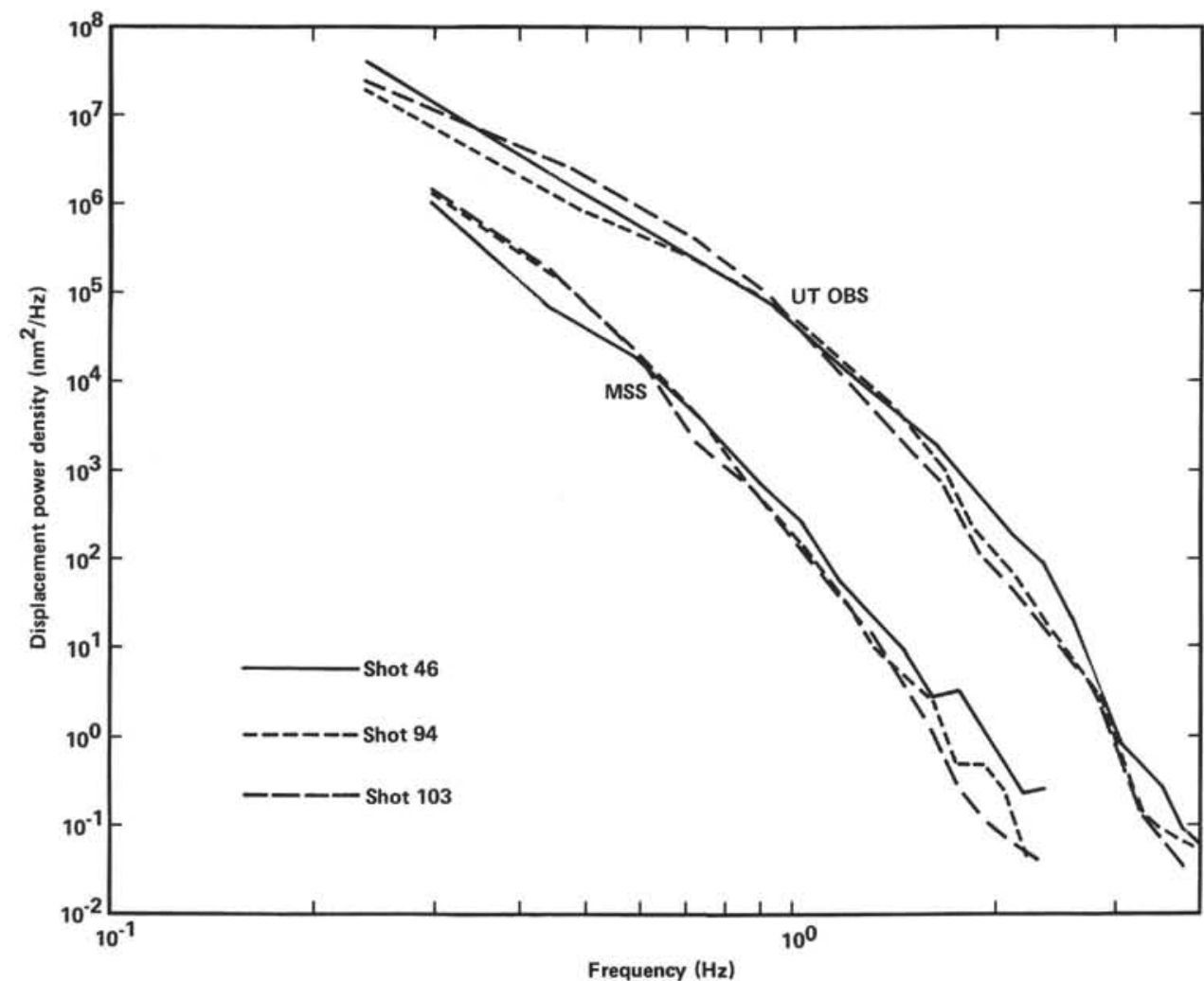

Figure 13. Comparison of corrected UT OBS and MSS noise observations recorded during refraction experiment windows when shots failed to explode. Curves in the upper set were computed from UT OBS data, those in the bottom set from MSS data. The UT OBS was programmed to record a maximum of $40 \mathrm{~s}$ per event, but in practice only $34.2 \mathrm{~s}$ of data (4096 samples) were available for analysis. Eight segments of 512 time points were used to calculate the estimates for both the UT OBS and MSS data. 


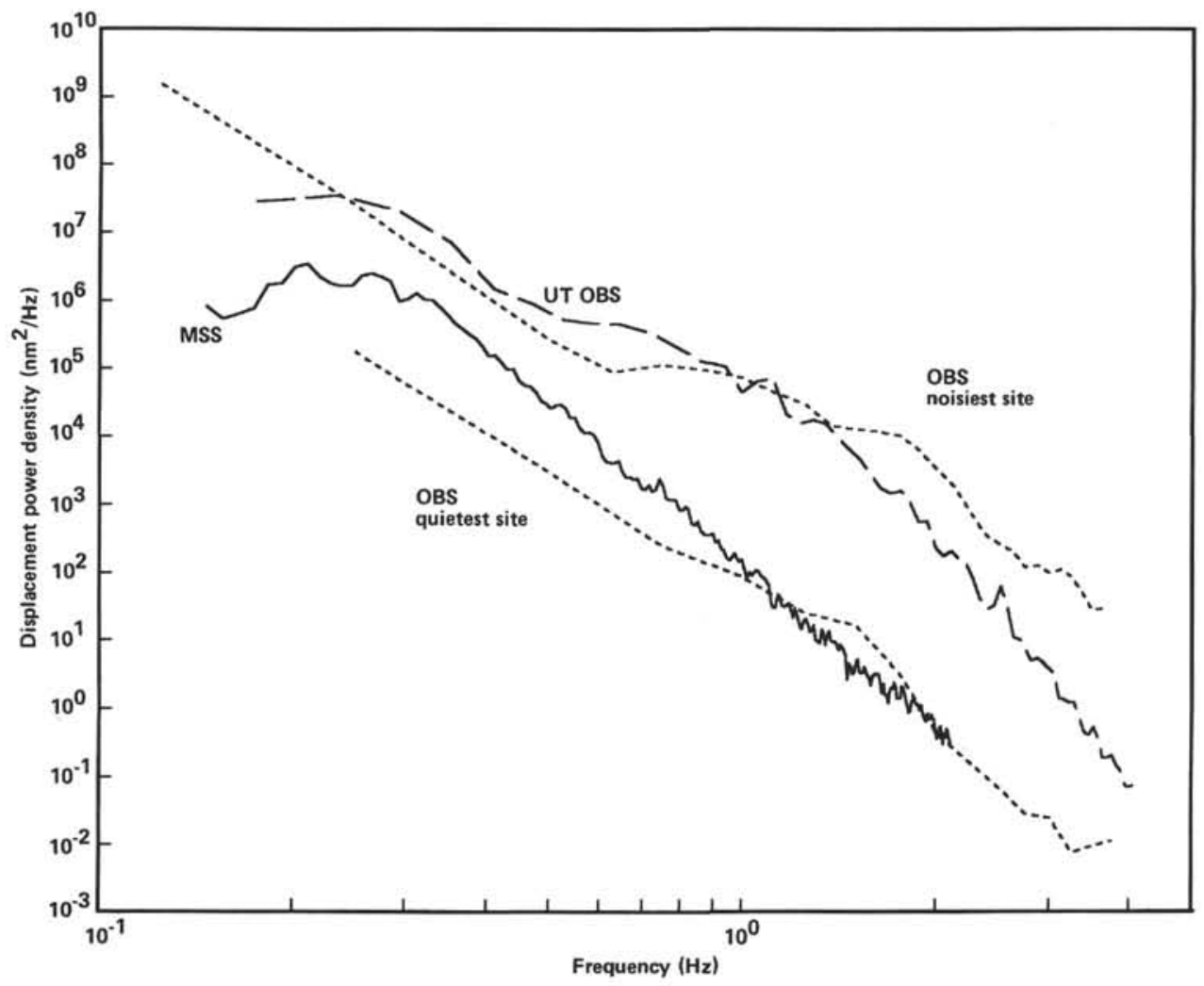

Figure 14. Comparison of Leg 78B noise spectra with OBS observations in the Pacific. The UT OBS data are the same as those in Figure 12; the MSS data are the earliest (and therefore lowest) of those in Figure 10. The two dashed curves are extrema of observations made with the Scripps Institution of Oceanography OBSs. The "noisiest site" was southeast of Hawaii, and the data were fifty-four 8-s samples; the "quietest site" was on the East Pacific Rise, and the data were thirty-one 4-s samples. 


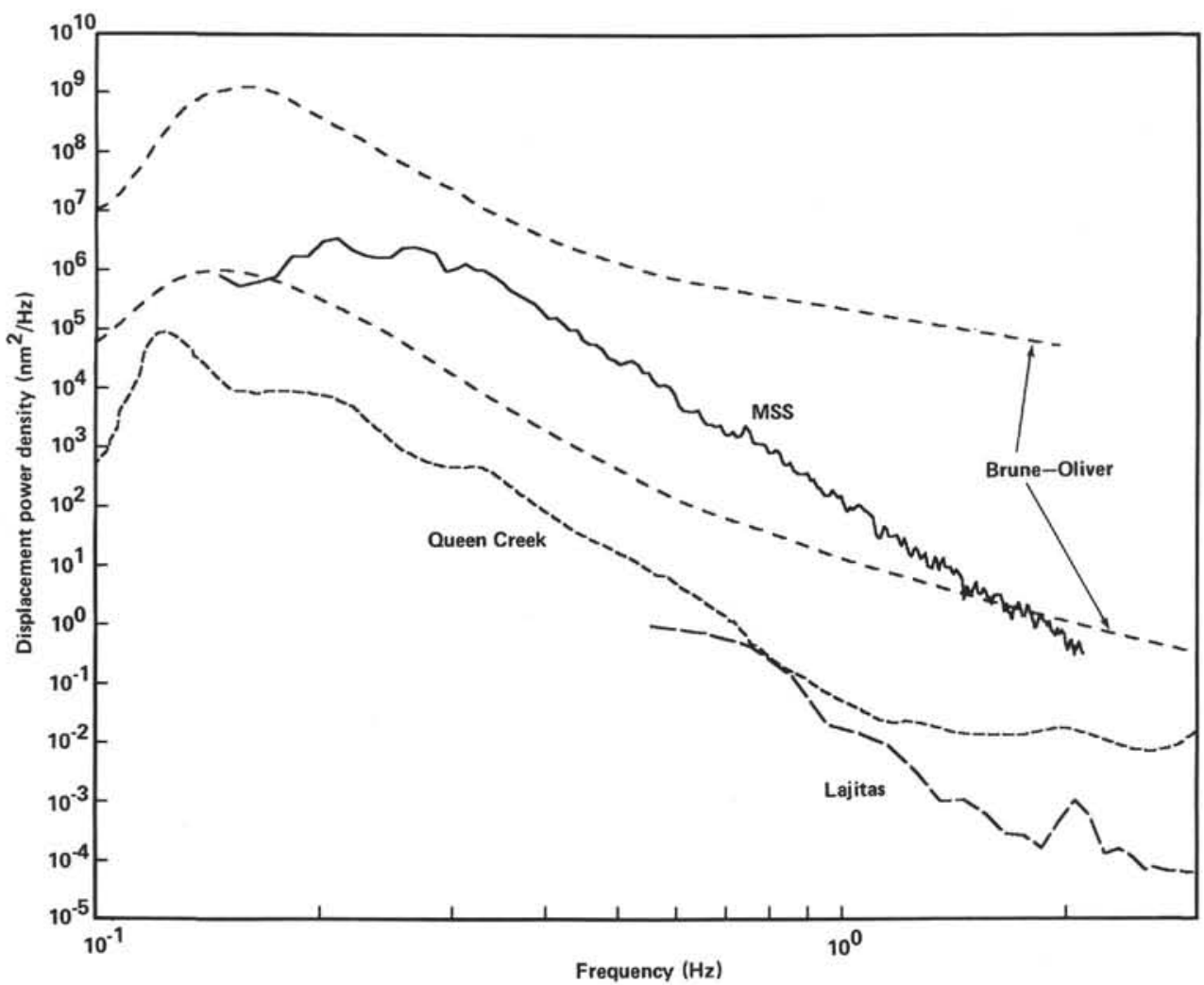

Figure 15. Comparison of the sub-bottom noise spectrum at Site 395 with spectra at two quiet continental sites. The Queen Creek, Arizona curve was taken from Melton (1976), who extracted it from Fix (1972). The Lajitas, Texas data were recorded at an extremely quiet surface site during a time of low winds (Herrin, 1982). Brune-Oliver (1959) curves are from Melton (1976). 